\title{
Insulin receptor substrate 2 plays a crucial role in $\beta$ cells and the hypothalamus
}

\author{
Naoto Kubota,, 1,2,3,4 Yasuo Terauchi,,1,2 Kazuyuki Tobe,,1,2 Wataru Yano,, ${ }^{1}$ Ryo Suzuki, ${ }^{1,2}$ Kohjiro Ueki, \\ Iseki Takamoto, ${ }^{1,2}$ Hidemi Satoh, ${ }^{1}$ Toshiyuki Maki, ${ }^{1}$ Tetsuya Kubota, ${ }^{5}$ Masao Moroi, ${ }^{5}$ \\ Miki Okada-Iwabu, ${ }^{4}$ Osamu Ezaki, 6 Ryozo Nagai, ${ }^{7}$ Yoichi Ueta, ${ }^{8}$ \\ Takashi Kadowaki,1,2,4 and Tetsuo Noda ${ }^{3,9}$
}

${ }^{1}$ Department of Metabolic Diseases, Graduate School of Medicine, University of Tokyo, Tokyo, Japan. ${ }^{2}$ Core Research for Evolutional Science and Technology (CREST), Japan Science and Technology Corporation, Saitama, Japan. ${ }^{3}$ Department of Cell Biology, Japanese Foundation for Cancer Research Cancer Institute, Tokyo, Japan. ${ }^{4}$ Division of Applied Nutrition, National Institute of Health and Nutrition, Tokyo, Japan. ${ }^{5}$ Third Department of Internal Medicine, Toho University School of Medicine, Ohashi Hospital, Tokyo, Japan. ${ }^{6}$ Division of Clinical Nutrition, National Institute of Health and Nutrition, Tokyo, Japan. ${ }^{7}$ Department of Cardiovascular Diseases, Graduate School of Medicine, University of Tokyo, Tokyo, Japan. ${ }^{8}$ Department of Physiology, School of Medicine, University of Occupational and Environmental Health, Kitakyushu, Japan. ${ }^{9}$ Department of Molecular Genetics, Tohoku University School of Medicine, Sendai, Japan.

\begin{abstract}
We previously demonstrated that insulin receptor substrate 2 (Irs2) KO mice develop diabetes associated with hepatic insulin resistance, lack of compensatory $\beta$ cell hyperplasia, and leptin resistance. To more precisely determine the roles of Irs 2 in $\beta$ cells and the hypothalamus, we generated $\beta$ cell-specific Irs $2 \mathrm{KO}$ and hypothalamus-specific Irs2 knockdown ( $\beta$ HT-IRS2) mice. Expression of Irs 2 mRNA was reduced by approximately $90 \%$ in pancreatic islets and was markedly reduced in the arcuate nucleus of the hypothalamus. By contrast, Irs2 expression in liver, muscle, and adipose tissue of $\beta$ HT-IRS2 mice was indistinguishable from that of control mice. The $\beta$ HT-IRS 2 mice displayed obesity and leptin resistance. At 4 weeks of age, the $\beta H T$-IRS 2 mice showed normal insulin sensitivity, but at 8 and 12 weeks, they were insulin resistant with progressive obesity. Despite their normal insulin sensitivity at 8 weeks with caloric restriction, the $\beta$ HT-IRS2 mice exhibited glucose intolerance and impaired glucose-induced insulin secretion. $\beta$ Cell mass and $\beta$ cell proliferation in the $\beta$ HT-IRS 2 mice were reduced significantly at 8 and 12 weeks but not at 10 days. Insulin secretion, normalized by cell number per islet, was significantly increased at high glucose concentrations in the $\beta$ HT-IRS 2 mice. We conclude that, in $\beta$ cells and the hypothalamus, Irs 2 is crucially involved in the regulation of $\beta$ cell mass and leptin sensitivity.
\end{abstract}

\section{Introduction}

The pathogenesis of type 2 diabetes involves complex interactions among multiple physiological defects. Transgenic and $\mathrm{KO}$ technologies that allow the creation of animal models of type 2 diabetes have had a major impact on the assessment of newly identified molecules implicated in the regulation of glucose homeostasis in vivo (1). Insulin receptor substrates 1 and 2 (Irs1 and Irs2) are 2 major substrates for insulin receptor tyrosine kinase and IGF receptor kinase (2-6), and the physiological roles of these proteins have been evaluated by gene targeting strategies (7). Irs1 $\mathrm{KO}\left(\operatorname{Irs} 1^{-/-}\right)$mice are growth-retarded and insulin-resistant $(8,9)$ but because of compensatory hyperinsulinemia associated with $\beta$ cell hyperplasia in response to insulin resistance, they do not develop diabetes (10).

Irs2 $2^{-/}$mice, on the other hand, develop type 2 diabetes associated with hepatic insulin resistance, lack of compensatory $\beta$ cell hyperplasia, and leptin resistance (11-14). In fact, we previously reported that at 6 and 12 weeks of age, $\beta$ cell mass in Irs $2^{-/-}$mice was reduced to $83 \%$ and $51 \%$, respectively, of that in WT mice (13). The Irs $2^{-/-}$mice displayed leptin resistance; and a low dose of leptin

\footnotetext{
Nonstandard abbreviations used: Foxo1, forkhead transcription factor 1; Hnf, hepatocyte nuclear factor; $\beta$ HT-IRS2, $\beta$ cell-specific Irs $2 \mathrm{KO}$ and hypothalamusspecific Irs2 knockdown; Irs, insulin receptor substrate; Irs $1^{-/-}$, Irs1 KO; Irs $2^{l o x / l o x}$, Irs2 floxed; neoR, neomycin-resistance gene; $\mathrm{Pdx} 1$, pancreas duodenum homeobox gene 1 ; RIP-Cre mice, mice expressing Cre under control of the rat insulin II promoter; Stat3, signal transducer and activator of transcription 3 ; tv, targeting vector; WAT, white adipose tissue.

Conflict of interest: The authors have declared that no conflict of interest exists.

Citation for this article: J. Clin. Invest. 114:917-927 (2004)

doi:10.1172/JCI200421484.
}

that was adequate to reduce food intake and body weight in WT mice had no effect in Irs $2^{-/-}$mice (14). However, since insulin resistance caused by the absence of Irs 2 in peripheral tissues may affect leptin sensitivity and $\beta$ cell proliferation, disruption of the Irs 2 gene specifically in $\beta$ cells and the hypothalamus would be required to more precisely determine the roles of Irs 2 at these sites. In the present study, we generated $\beta$ cell-specific Irs $2 \mathrm{KO}$ and hypothalamusspecific Irs2 knockdown ( $\beta$ HT-IRS2) mice by crossing Irs2 floxed mice $\left(\operatorname{Irs} 2^{l o x / l o x}\right)$ and transgenic mice expressing Cre under control of the rat insulin II promoter (RIP-Cre mice). Expression of Irs2 mRNA in the $\beta$ HT-IRS 2 mice was reduced by approximately $90 \%$ in the islets and markedly reduced in the arcuate nucleus of the hypothalamus, whereas liver, muscle and adipose tissue expressions in $\beta$ HT-IRS2 and control mice were indistinguishable. The $\beta$ HT-IRS2 mice were obese and leptin resistant. Furthermore, despite normal insulin sensitivity, these mice also displayed glucose intolerance and impaired glucose-induced insulin secretion. Both $\beta$ cell mass and $\beta$ cell proliferation in the $\beta$ HT-IRS 2 mice were significantly reduced at 8 and 12 weeks, but not at 10 days, and insulin secretion in these mice, normalized by cell number per islet, was significantly increased at high glucose concentrations. In conclusion, Irs 2 in $\beta$ cells and the hypothalamus plays crucial roles in the regulation of $\beta$ cell mass and leptin sensitivity.

\section{Results}

Generation of $\beta$ HT-IRS 2 mice. Irs $2^{\text {lox } / l o x}$ mice were generated by homologous recombination (Figure 1, A and B). We first performed a genomic DNA PCR analysis to detect Cre-mediated recombination at the genomic DNA level. Irs2 alleles were not deleted in any of 
the tissues of the Irs $2^{l o x} /$ lox mice (Figure 1C), but they were almost completely deleted in the islets and partially (50\%) deleted in the hypothalami of Irs $2^{l o x} /$ lox $/$ RIP-Cre mice (Figure 1C). Next, we investigated the expression levels of Cre mRNA and Irs 2 mRNA in the livers, skeletal muscles, adipose tissues, hypothalami, and pancreatic islets of WT, RIP-Cre, Irs $2^{\text {lox } / l o x}$, and Irs $2^{\text {lox } / l o x} / \mathrm{RIP}-\mathrm{Cre}$ mice. RT-PCR detected Cre mRNA expression in pancreatic $\beta$ cells of the RIP-Cre and Irs $2^{l o x} /$ lox $/$ RIP-Cre mice, but not in hepatic, skeletal muscle, or adipose tissues (Figure 1D). Although Cre recombinase was under the control of the rat insulin II promoter, Cre mRNA was also detected in the hypothalami of the Irs $2^{\text {lox }} /$ lox $/$ RIP-Cre and RIP-Cre mice (Figure 1D), suggesting that Irs2 deletion had also occurred in the hypothalamus. In fact, although no differences in Irs 2 mRNA levels between genotypes were detected in hepatic, skeletal muscle or adipose tissues (Figure 1D), Irs2 mRNA levels in islets were markedly reduced in the Irs $2^{\text {lox }} /$ lox $/$ RIP-Cre mice (Figure 1D), and Irs2 mRNA levels in the hypothalamus were partially (50\%) reduced in the Irs $2^{l o x} / l o x /$ RIP-Cre mice (Figure 1D). These findings indicate that the Irs $2^{l o x} /$ lox $/$ RIP-Cre mice were $\beta$ HT-IRS 2 mice.

\section{Figure 1}

Generation of $\beta \mathrm{HT}$-IRS2 mice. (A) Schematic representation of the 3 steps in our gene-targeting strategy. (B) Southern blot analysis. Left: Sacl-digested ES cell genomic DNA hybridized with probe A. The 4-kb band corresponds to the WT (+) allele, and the 3.2-kb band to the first step of the mutant (neo) allele. Middle: Spel- and EcoRV-digested ES cell genomic DNA hybridized with probe $\mathrm{B}$. The 11.8-kb band corresponds to the WT (+) allele, the 2.9-kb band to the (neo) allele, and the $1.6-\mathrm{kb}$ band to the second step of the mutant $(\Delta)$ allele. Right: HindIII-digested ES cell genomic DNA hybridized with probe $C$. The 17.3-kb band corresponds to the WT (+) allele, the 15.2-kb band to the mutant $(\Delta)$ allele, and the 6-kb band to final step of the mutant (neo $\Delta$ ) allele. (C) PCR analysis of genomic DNA to detect Cre-mediated recombination. K, kidney; L, liver; M, muscle; A, adipose tissue; $\mathrm{S}$, spleen; HT, hypothalamus; $H$, heart; Lu, lung; I, islet. (D) RT-PCR of Cre and Irs2 expression in liver, skeletal muscle, adipose tissue, hypothalami, and pancreatic islets of WT, RIP-Cre, IRS2 $2^{\text {lox } / \text { ox }}$, and IRS2/ox/lox/RIP-Cre ( $\beta$ HT-IRS2) mice. (E) Western blot analysis of Irs2 in pancreatic islets (upper panel) and hypothalami (lower panel) from control and $\beta \mathrm{HT}$-IRS2 mice.
Given the similar expression levels of Irs 2 in $\beta$ cells and the hypothalamus among WT, RIP-Cre, and Irs $2^{l o x} /$ lox mice, which indicates that neither insertion of the loxP and neomycin-resistance gene $(n e o R)$ sites nor expression of Cre recombinase alone affected the abundance of Irs2, we performed subsequent experiments using Irs $2^{\text {lox/lox }}$ (control) and $\beta$ HT-IRS2 mice. Irs 2 protein was not detected in islets and was partially (50\%) reduced in the hypothalami of $\beta$ HT-IRS2 mice (Figure 1E).

$\beta$ HT-IRS2 mice show leptin resistance. The body weight of the $\beta$ HTIRS2 mice was significantly higher than that of the control mice from 5 weeks onward (Figure 2A). The white adipose tissue (WAT) mass of the epididymal fat pads was also significantly higher in
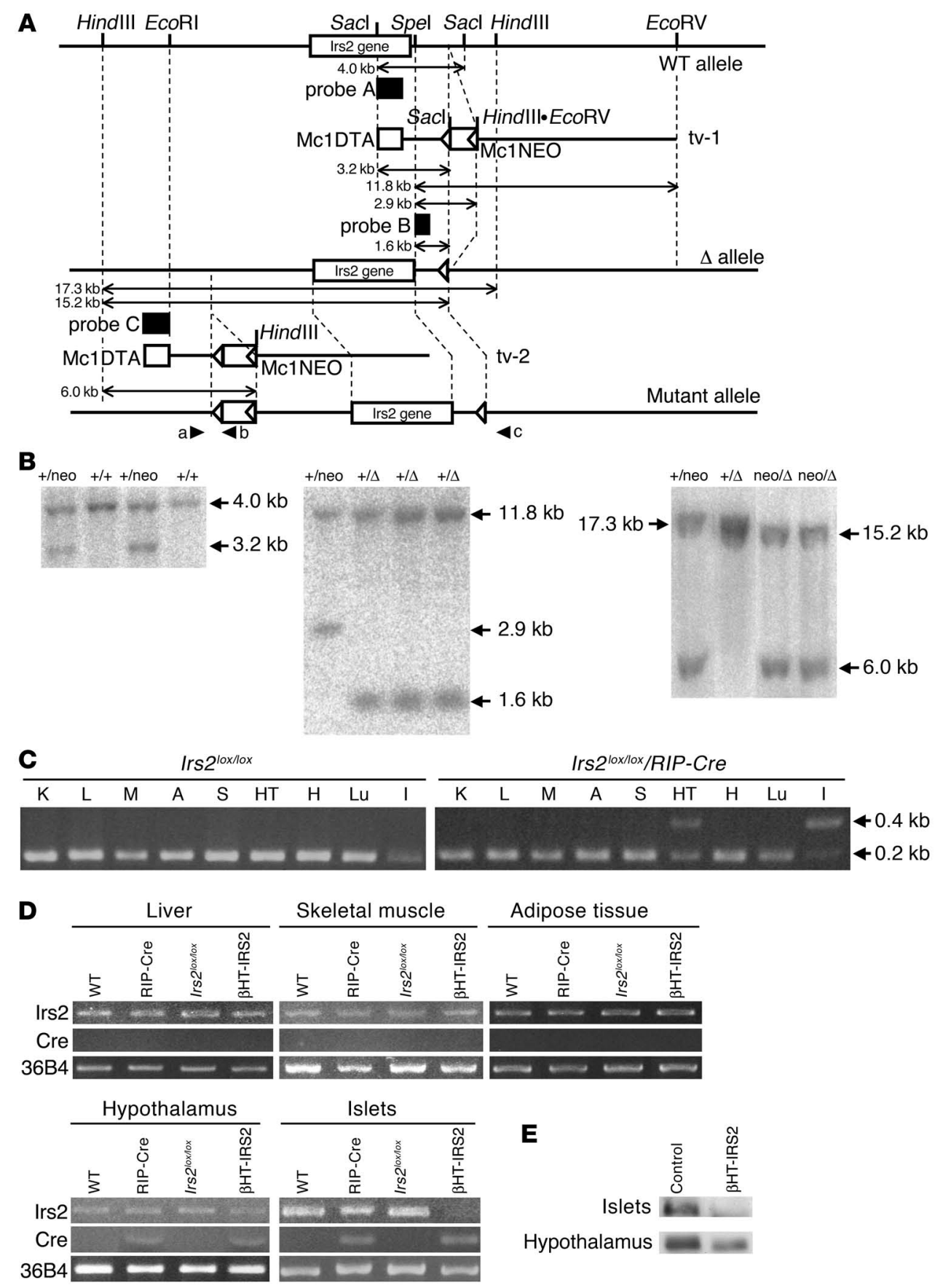

Hypothalamus 
A
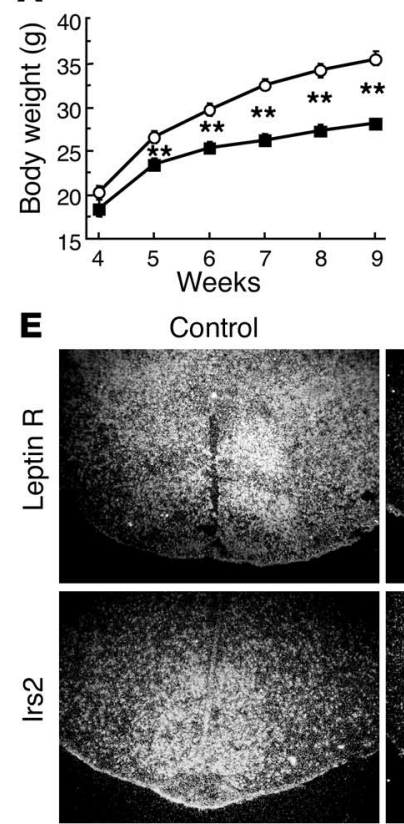

B

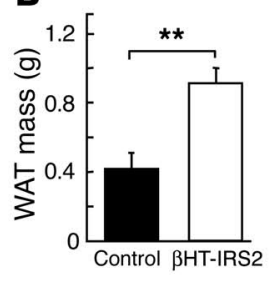

$\beta$ HT-IRS2

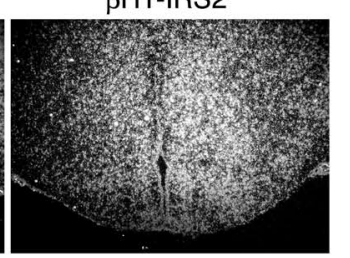

C
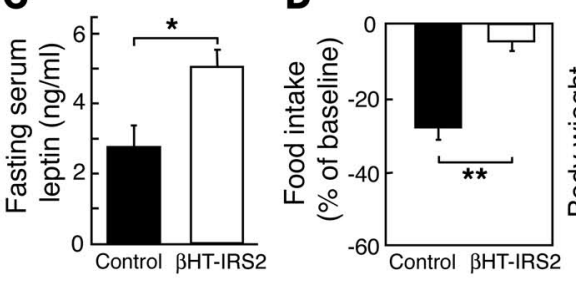
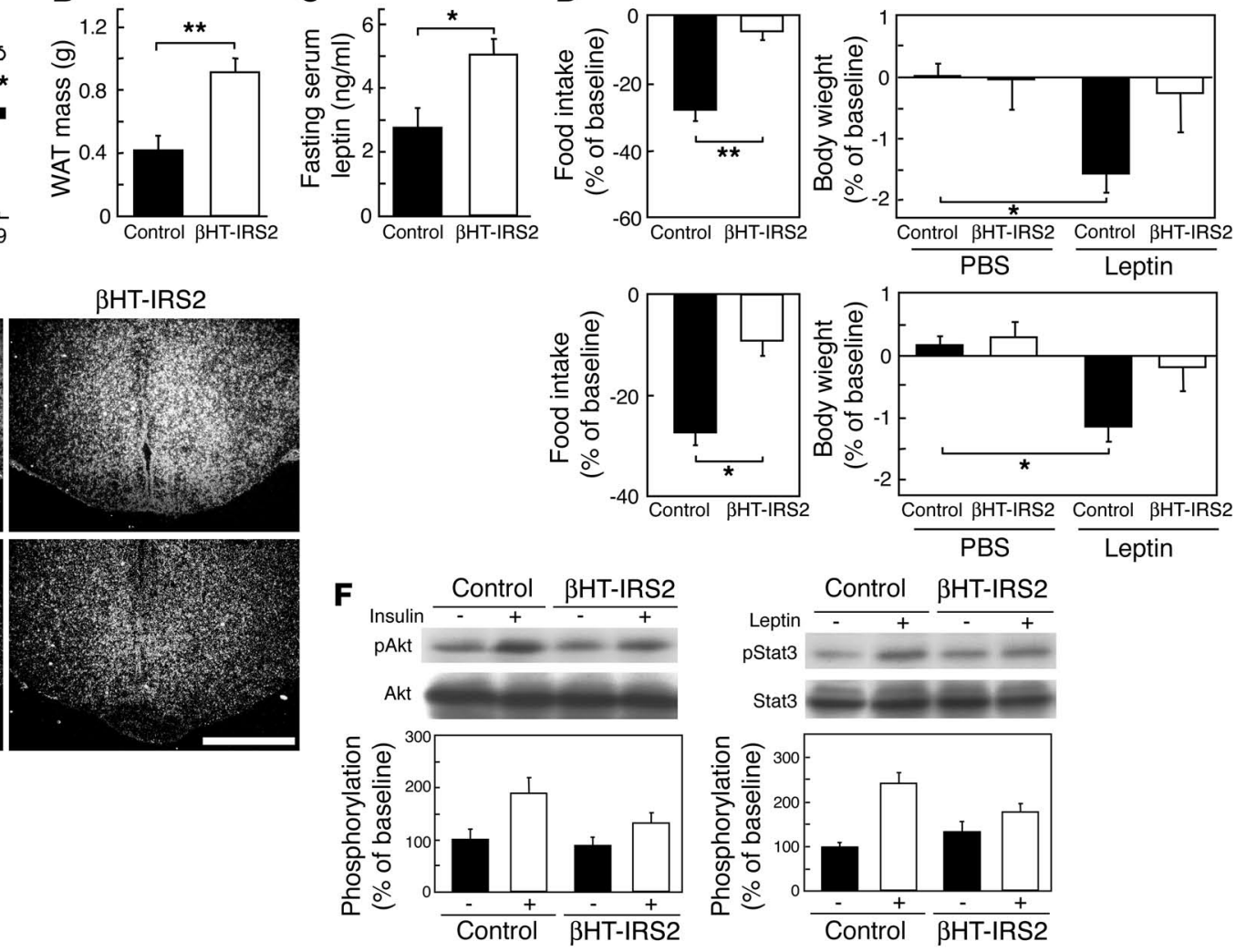

\section{Figure 2}

$\beta$ HT-IRS2 mice showed leptin resistance. (A) Body weights of control and $\beta \mathrm{HT}$-IRS2 mice. Values are means \pm SE of data obtained from the analysis of control (filled squares, $n=10$ ) and $\beta \mathrm{HT}$-IRS2 mice (open circles, $n=11$ ). (B) WAT mass of epididymal fat pads of control and $\beta \mathrm{HT}$ IRS2 mice at 12 weeks. Values are means \pm SE of data obtained from the analysis of control (black bar, $n=5$ ) and $\beta \mathrm{HT}$-IRS2 mice (white bar, $n=9$ ). (C) Fasting serum leptin levels of control and $\beta \mathrm{HTT}$-IRS2 mice at 8 weeks. Values are means \pm SE of data obtained from the analysis of control (black bar, $n=10$ ) and $\beta$ HT-IRS2 mice (white bar, $n=11$ ). (D) Leptin-mediated suppression of food intake (left) and body weight (right) at 8 weeks. Baseline food intake was measured during PBS injection. Values are means \pm SE of data obtained from the analysis of control (black bar, $n=9$ ) and $\beta$ HT-IRS2 mice (white bar, $n=7$ ). (E) In situ hybridization of the leptin receptor and Irs2 in hypothalami from control and $\beta$ HT-IRS2 mice. Scale bar represents $1 \mathrm{~mm}$. (F) Insulin-stimulated phosphorylation of Akt (top) and leptin-stimulated phosphorylation of Stat3 (bottom). Upper panels: lysates from untreated and insulin-treated mice were immunoblotted for anti-phospho-Akt (pAkt) and anti-Akt. Lower panels: lysates from untreated and leptin-treated mice were immunoblotted for anti-phospho-Stat3 (pStat3) and anti-Stat3. In graphs, white bars represent insulin- (left) or leptin- (right) stimulated phosphorylation. Data (means \pm SE) are representative of at least 3 independent experiments. ${ }^{*} P<0.05$; ${ }^{* \star} P<0.01$.

the $\beta$ HT-IRS2 mice than in the control mice at 12 weeks (Figure $2 \mathrm{~B})$. At 8 weeks, fasting serum leptin levels were significantly higher in $\beta$ HT-IRS2 mice than in control mice (Figure $2 \mathrm{C}$ ), suggesting the former to be leptin-resistant. To assess leptin sensitivity directly, we compared the responses of $\beta$ HT-IRS 2 mice and control mice to exogenous leptin. Suppression of food intake was significantly smaller in the $\beta$ HT-IRS2 mice than in the control mice, and body weight was significantly suppressed in the control mice, but not in the $\beta$ HT-IRS2 mice (Figure 2D, upper panels). To rule out the possibility that this leptin resistance may be secondary to obesity, we next assessed leptin sensitivity in 8 -week-old $\beta$ HT-IRS2 mice that were pair-fed with control mice for 4 weeks, starting from 4 weeks of age. Pair-fed $\beta$ HT-IRS 2 mice did not become obese; their body weights were identical to those of controls. Suppression of food intake was significantly reduced in the $\beta$ HT-IRS2 mice as compared with the control mice, and body weight was significantly suppressed in the control mice, but not in the $\beta$ HT-IRS2 mice (Figure 2D, lower panels).
To further confirm that Irs2 was deleted in the hypothalamus, especially in leptin receptor-positive areas, we performed in situ hybridization on brain sections that included the hypothalamus. We found that Irs 2 expression was markedly reduced throughout the leptin receptor-positive areas in the arcuate nucleus of the hypothalamus (Figure 2E). Quantitative analyses showed Irs2 expression levels in hypothalami from $\beta$ HT-IRS2 mice to be significantly decreased as compared with those in control mice $(1.61 \pm 0.01 \mathrm{kBq} / \mathrm{g}$ in control vs. $0.86 \pm 0.05 \mathrm{kBq} / \mathrm{g}$ in $\beta$ HT-IRS2, $P<0.001)$. To assess insulin and leptin signaling in the hypothalami of $\beta$ HT-IRS2 mice, we conducted Western blot analyses. Insulin-stimulated phosphorylation of Akt in these mice was reduced to $49 \%$ of the level seen in control mice (Figure $2 \mathrm{~F}$, left panel). Leptin-stimulated phosphorylation of signal transducer and activator of transcription 3 (Stat3) in these mice was also reduced by $42 \%$ as compared with that in control mice (Figure $2 \mathrm{~F}$, right panel), suggesting that both insulin and leptin signaling were attenuated in the $\beta$ HT-IRS2 hypothalamus. 
$\beta$ HT-IRS2 mice show insulin resistance, glucose intolerance, and dyslipidemia. Unlike Irs $2^{-/-}$mice $(11,13)$, the $\beta$ HT-IRS2 mice did not exhibit fasting glucose and insulin elevation at 8 weeks (Figure 3A). Random blood glucose determinations yielded similar levels in $\beta$ HT-IRS2 and control mice at both 8 weeks and 12 weeks (Figure 3B). Investigation of insulin sensitivity by means of insulin tolerance tests showed no significant difference between $\beta \mathrm{HT}$ IRS2 and control mice at 4 weeks (Figure 3C, upper left panel). At 8 and 12 weeks, however, the glucoselowering effect of insulin was significantly smaller in the $\beta$ HT-IRS 2 mice, suggesting that increased body weight in these mice at 8 and 12 weeks is associated with insulin resistance (Figure 3C, upper right and lower left panels). In fact, when the body weights of the $\beta$ HT-IRS 2 and control mice became similar during 4-week caloric restriction, the glucose-lowering effects of insulin became indistinguishable between the two groups at 8 weeks (Figure 3C, lower right panel). Next, we investigated glucose tolerance in $\beta$ HT-IRS2 and control mice by means of the oral glucose tolerance tests at 8 weeks, both with caloric restriction (Figure $2 \mathrm{D}$, upper panels) and without caloric restriction (Figure 2D, lower panels). After glucose loading, the blood glucose levels of both groups were significantly higher in $\beta$ HT-IRS2 mice than in control mice (Figure 3D, left panels). The plasma insulin levels of both groups after the glucose load were significantly lower in $\beta \mathrm{HT}$ IRS2 mice than in control mice (Figure 3D, right panels). These findings indicate that glucose intolerance in $\beta$ HT-IRS2 mice is attributable to impaired glucoseinduced insulin secretion. Assessment of lipid metabolism revealed significantly higher serum total cholesterol and triglyceride levels in $\beta$ HT-IRS2 mice than in

\section{Figure 3}

$\beta$ HT-IRS2 mice showed insulin resistance, glucose intolerance, and dyslipidemia. (A) Fasting glucose (left) and insulin levels (right) of control and $\beta \mathrm{HT}$-IRS2 mice at 8 weeks. Values are means \pm SE of data obtained from the analysis of control (black bar, $n=12$ ) and $\beta$ HT-IRS2 mice (white bar, $n=13$ ). (B) Random blood glucose levels of control and $\beta \mathrm{HT}$ TIRS2 mice at 8 and 12 weeks. Values are means \pm SE of data obtained from the analysis of control (black bar, $n=12$ ) and $\beta$ HT-IRS2 mice (white bar, $n=13$ ). (C) Insulin tolerance tests of control and $\beta \mathrm{HT}$-IRS2 mice at 4 weeks (upper left), 8 weeks (upper right), 12 weeks (lower left), and 8 weeks with 4-week caloric restriction (lower right). Values are means \pm SE of data obtained from the analysis of control (filled squares, $n=8-14$ ) and $\beta$ HT-IRS2 mice (open circles, $n=9-14$ ). (D) Oral glucose tolerance tests of control and $\beta \mathrm{HT}$-IRS2 mice at 8 weeks with caloric restriction (upper) and without caloric restriction (lower). Values are means \pm SE of data obtained from the analysis of control (filled squares, $n=8-10$ ) and $\beta$ HT-IRS2 mice (open circles, $n=9-10$ ). Blood glucose (left) and plasma insulin levels (right) were measured at the times indicated. (E) Serum total cholesterol (left), triglyceride (middle), and FFA (right) levels of the control and $\beta \mathrm{HT}$ TIRS2 mice at 8 weeks. Values are means \pm SE of data obtained from the analysis of control (black bar, $n=10$ ) and $\beta$ HT-IRS2 mice (white bar, $n=10)$. ${ }^{\star} P<0.05 ;{ }^{* *} P<0.01$. control mice (Figure 3E, left and middle panels), while their serum free fatty acid levels were similar (Figure 3E, right panel).

$\beta$ Cell mass and $\beta$ cell proliferation are reduced in $\beta$ HT-IRS 2 mice at 8 and 12 weeks. Next, we performed histological and immunohistological analyses of pancreatic islets of 8-week-old mice that had or had not been subjected to caloric restriction. We observed no insulin resistance in the former group and mild insu-
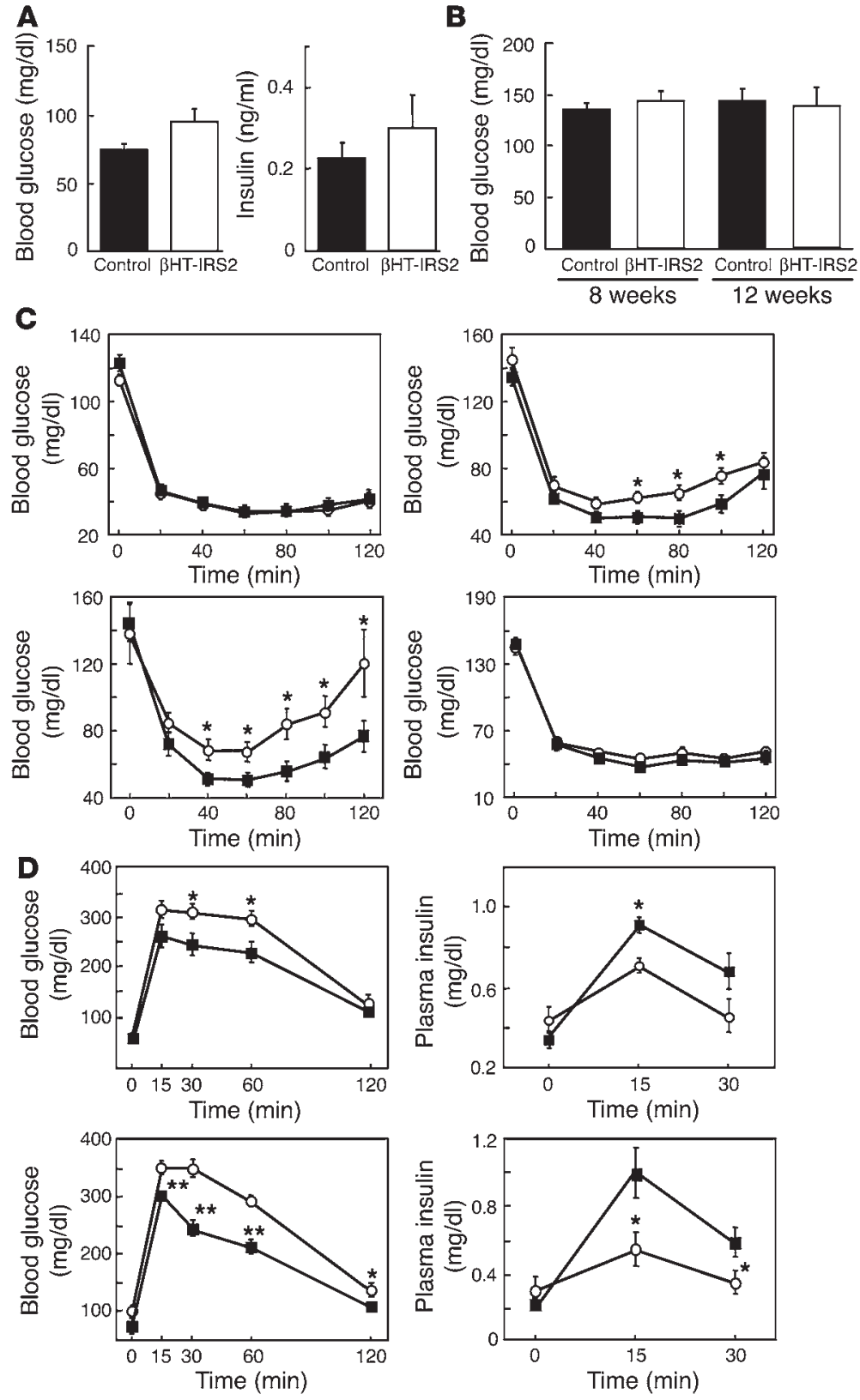

E
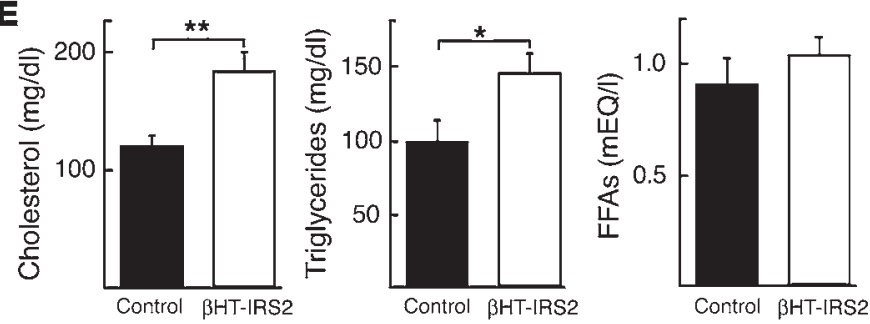
A

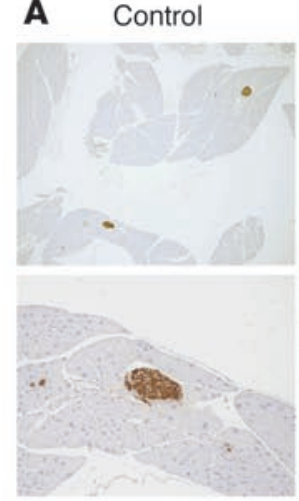

B Control
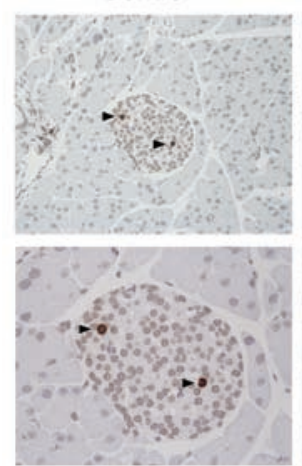

$\beta$ HT-IRS2

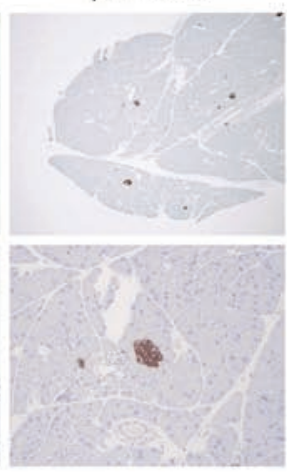

BHT-IRS2
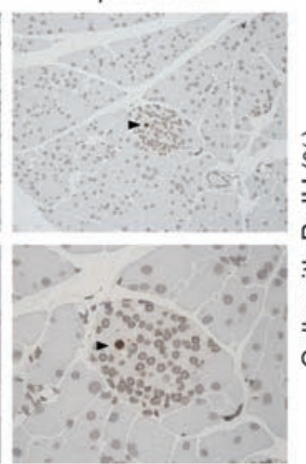
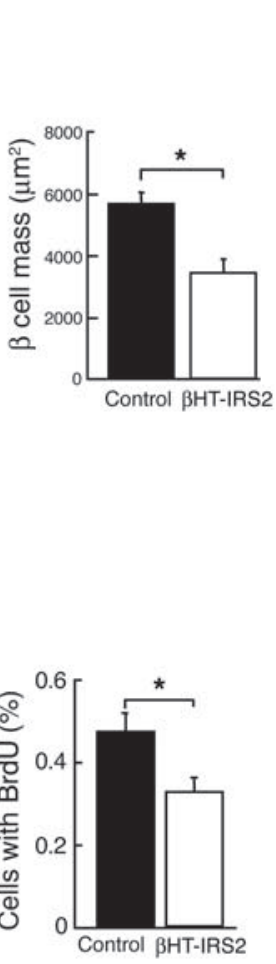

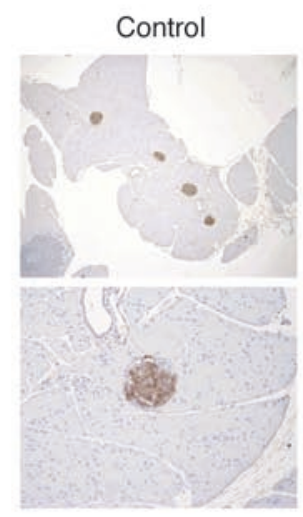

Control

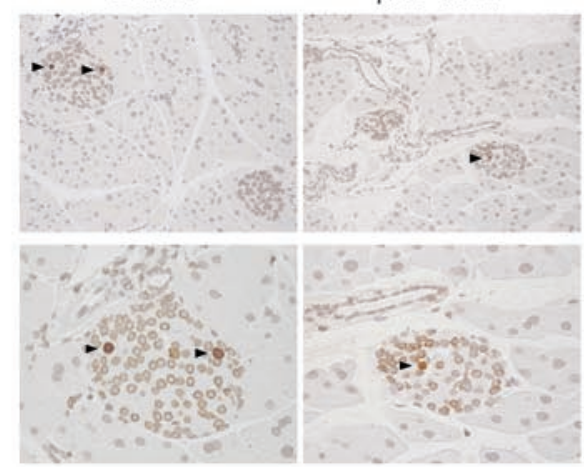

BHT-IRS2
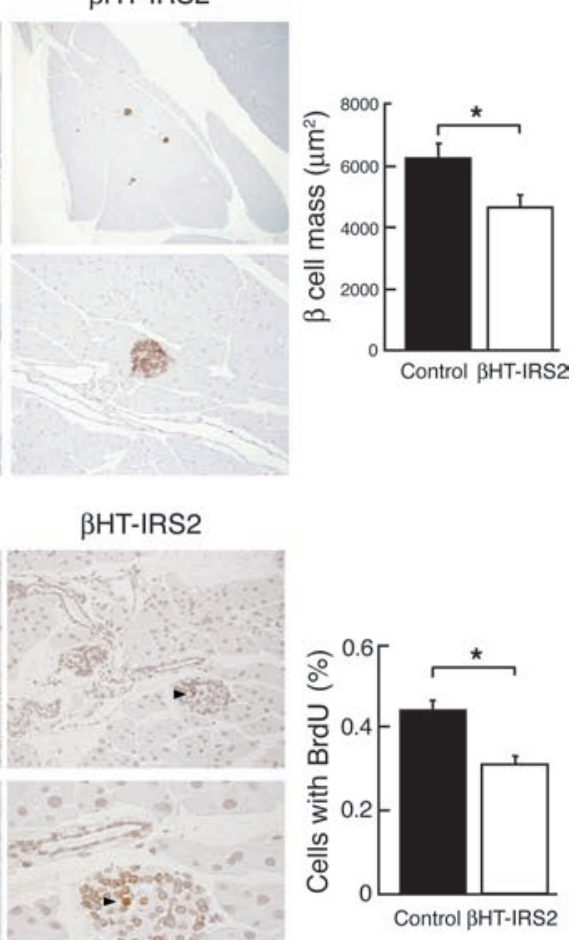

Figure 4

$\beta$ Cell mass and $\beta$ cell proliferation were reduced in $\beta$ HT-IRS2 mice at 8 weeks, regardless of caloric restriction. (A) Histological analysis of pancreatic islets (upper) and quantitation of $\beta$ cell mass (lower) in control and $\beta$ HT-IRS2 mice at 8 weeks with caloric restriction (left panels) and without caloric restriction (right panels). Representative islets viewed on a computer monitor are shown. Results are shown as area of $\beta$ cell mass. Values are means \pm SE of data obtained from the analysis of control (black bars, $n=5$ ) and $\beta$ HT-IRS2 mice (white bars, $n=5$ ). Original magnification, $\times 40$ (upper panels); $\times 100$ (lower panels). (B) BrdU incorporation into $\beta$ cell nuclei of control and $\beta \mathrm{HT}$-IRS2 mice at 8 weeks with caloric restriction (left panels) and without caloric restriction (right panels). Results are shown as percentages of cells that incorporated BrdU. Values are means \pm SE of data obtained from the analysis of control (black bars, number of islets $=192-197$ ) and $\beta$ HT-IRS2 mice (white bars, number of islets $=211-232$ ). Original magnification, $\times 100$ (upper panels); $\times 400$ (lower panels). Arrowheads indicate cells that have incorporated BrdU. ${ }^{*} P<0.05$.

lin resistance in the latter group (Figure 4A). The $\beta$ cell mass did not differ between the groups with and without caloric restriction. Similar to the Irs $2^{-/-}$mice $(11,13)$, however, the $\beta$ cell mass of the $\beta$ HT-IRS 2 mice was significantly reduced as compared to that of the control mice in both groups (Figure 4A). Decreased $\beta$ cell mass may be attributable to decreased proliferation and/or increased apoptosis. The percentage of cells incorporating BrdU in $\beta$ HT-IRS2 mice was significantly lower than that in control mice at 8 weeks in both groups (Figure 4B), but the percentage of cells containing single-strand DNA in $\beta$ HT-IRS 2 mice was indistinguishable from that in control mice, both with caloric restriction $(2.0 \%$ in $\beta$ HT-IRS2 vs. $1.8 \%$ in control, per 100 islets) and without caloric restriction ( $2.1 \%$ in $\beta$ HT-IRS2 vs. $2.3 \%$ in control, per 100 islets; data not shown).

We also performed histological and immunohistological analyses of pancreatic islets at 12 weeks to investigate the impact of insulin resistance. The $\beta$ cell mass in $\beta$ HT-IRS 2 mice was significantly reduced to $72 \%$ of that in control mice (Figure $5 \mathrm{~A}$ ). Measurements of BrdU incorporation into the $\beta$ cell nuclei of $\beta \mathrm{HT}$ IRS2 and control mice (Figure 5B) indicated that a significantly lower percentage of cells in $\beta$ HT-IRS2 mice incorporated BrdU, as compared to control mice (Figure 5B). $\beta$ Cell mass and $\beta$ cell proliferation are not reduced in $\beta$ HT-IRS 2 mice at 10 days. After the decreases in $\beta$ cell mass and BrdU incorporation were detected in the $\beta$ HT-IRS2 mice, we performed histological and immunohistological analyses of pancreatic islets at 10 days during the breastfeeding period. The body weights of the $\beta \mathrm{HT}$ IRS2 and control littermate mice were similar (Figure 6A). Random blood glucose determinations also yielded similar levels in the $\beta$ HT-IRS2 and control littermate mice (Figure 6B). Surprisingly, the $\beta$ cell masses of the $\beta$ HT-IRS 2 and control mice were not different (Figure 6C), and the percentages of cells incorporating BrdU did not differ significantly between the $\beta$ HT-IRS2 and control mice (Figure 6D), suggesting that pancreatic $\beta$ cell proliferation was not reduced in $\beta$ HT-IRS2 mice at 10 days.

Normal expression of pancreas duodenum homeobox gene 1, normal insulin content, and increased insulin secretion in $\beta H T-I R S 2$ mice. We next investigated the expression levels of pancreas duodenum homeobox gene 1 ( $\mathrm{Pdx} 1)$, a key transcription factor involved in pancreatic development and in the maintenance of $\beta$ cell function, in the islets of $\beta$ HT-IRS 2 and control mice. Immunohistochemical studies revealed $\mathrm{Pdx} 1$ protein to be equally expressed in the nuclei of $\beta$ HT-IRS 2 and control mice at 8 weeks (Figure 7A, left panel) and at 12 weeks (Figure 7A, right panel). In addition, Taqman PCR 
A Control

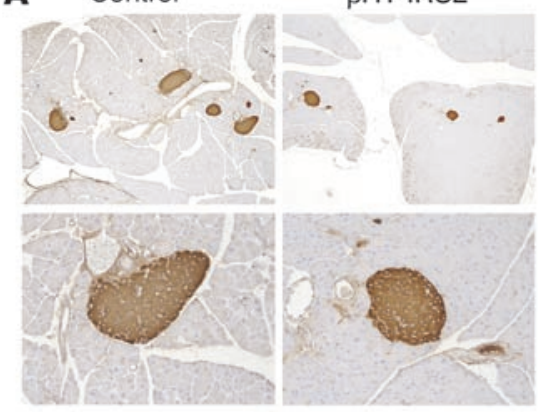

B

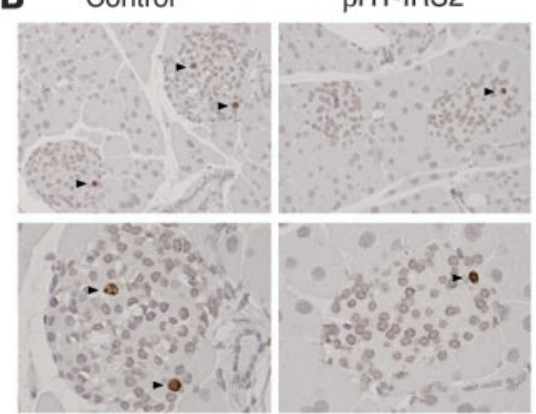

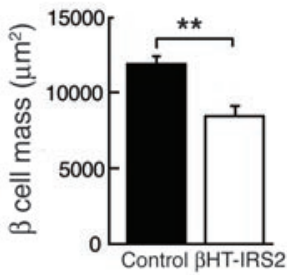

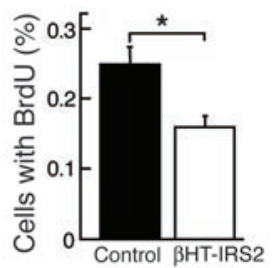

revealed the expression levels of Pdx1, hepatocyte nuclear factor $1 \alpha(\operatorname{Hnf} 1 \alpha), \operatorname{Hnf} 4 \alpha$, and forkhead transcription factor 1 (Foxo 1 ) mRNA in $\beta$ HT-IRS2 and control mice to be indistinguishable at 8 weeks (Figure 7B, left panel) and at 12 weeks (Figure 7B, right panel). We then measured glucose-induced insulin secretion in $\beta$ HT-IRS2 mice at 8 weeks by static incubation of the same numbers of islets for 1 hour. Whereas insulin secretions into the medium by islets from $\beta$ HT-IRS 2 and control mice were similar at 2.8 $\mathrm{mM}$ glucose, at $11.1 \mathrm{mM}$ glucose, insulin secretion by islets from the $\beta$ HT-IRS 2 mice was significantly greater than that from control islets (Figure 7C). This remained true when we normalized the measure of glucose-induced insulin secretion by cell number (Figure 7C). There was a significant reduction in insulin content per islet in $\beta$ HT-IRS2 mice as compared to that in control mice (Figure

\section{Figure 6}

$\beta$ Cell mass and $\beta$ cell proliferation were not reduced in $\beta$ HT-IRS2 mice at 10 days. (A) Body weights of control and $\beta$ HT-IRS2 mice. Values are means \pm SE of data obtained from the analysis of control (black bar, $n=4$ ) and $\beta$ HT-IRS2 mice (white bar, $n=4$ ). (B) Random blood glucose levels of control and $\beta$ HT-IRS2 mice. Values are means \pm SE of data obtained from the analysis of control (black bar, $n=4$ ) and $\beta \mathrm{HT}$ IRS2 mice (white bar, $n=4$ ). (C) Histological analysis of pancreatic islets (left) and quantitation of $\beta$ cell mass (right) in control and $\beta \mathrm{HT}$ IRS2 mice at 10 days. Representative islets viewed on a computer monitor are shown. Results are shown as area of $\beta$ cell mass. Values are means \pm SE of data obtained from the analysis of control (black bar, $n=4$ ) and $\beta$ HT-IRS2 mice (white bar, $n=4$ ). Original magnification, $\times 200$. (D) BrdU incorporation into $\beta$ cell nuclei of control and $\beta \mathrm{HT}$-IRS2 mice. Results are shown as the percentage of cells that had incorporated BrdU. Values are means \pm SE of data obtained from the analysis of control (black bar, number of islets $=67$ ) and $\beta$ HT-IRS2 mice (white bar, number of islets $=58$ ). Original magnification, $\times 400$ (upper panels); $\times 600$ (lower panels). Arrowheads indicate cells that have incorporated BrdU.

\section{Figure 5}

$\beta$ Cell mass and $\beta$ cell proliferation were reduced in $\beta$ HT-IRS2 mice at 12 weeks. (A) Histological analysis of pancreatic islets (left) and quantitation of $\beta$ cell mass (right) in control and $\beta$ HT-IRS2 mice at 12 weeks. Representative islets viewed on a computer monitor are shown. Results are shown as area of $\beta$ cell mass. Values are means \pm SE of data obtained from the analysis of control (black bar, $n=5$ ) and $\beta \mathrm{HT}$-IRS2 mice (white bar, $n=5$ ). Original magnification, $\times 40$ (upper panels); $\times 100$ (lower panels). (B) BrdU incorporation into $\beta$ cell nuclei of control and $\beta \mathrm{HT}$-IRS2 mice. Results are shown as percentages of cells that incorporated BrdU. Values are means \pm SE of data obtained from the analysis of control (black bar, number of islets $=280$ ) and $\beta \mathrm{HT}$-IRS2 mice (white bar, number of islets $=284$ ). Original magnification, $\times 100$ (upper panels); $\times 400$ (lower panels). Arrowheads indicate cells that have incorporated BrdU. ${ }^{*} P<0.05$.

$7 \mathrm{D}$, left). However, when normalized by cell number per islet, the insulin contents of the 2 genotypes were equivalent (Figure 7D, right). We next investigated the effect of LY294002, an inhibitor of PI3K, on glucose-induced insulin secretion in $\beta$ HT-IRS2 and control mice at 8 weeks. Both groups of mice exhibited similar insulin secretion with and without LY294002 at $2.8 \mathrm{mM}$ glucose. At $11.1 \mathrm{mM}$ glucose, insulin secretion with LY294002 in control mice was significantly higher than that without LY294002. Interestingly, insulin secretion in $\beta$ HT-IRS2 mice with LY294002 was significantly higher than that without LY294002 (Figure 7E).

$\beta$ HT-IRS2 mice on a high-fat diet. Glucose homeostasis of Irs $2^{-/-}$mice is reportedly affected by genetic background and environmental factors such as a high-fat diet (15). Therefore, we carried out a highfat diet study in $\beta$ HT-IRS2 mice. Mice were fed regular chow until
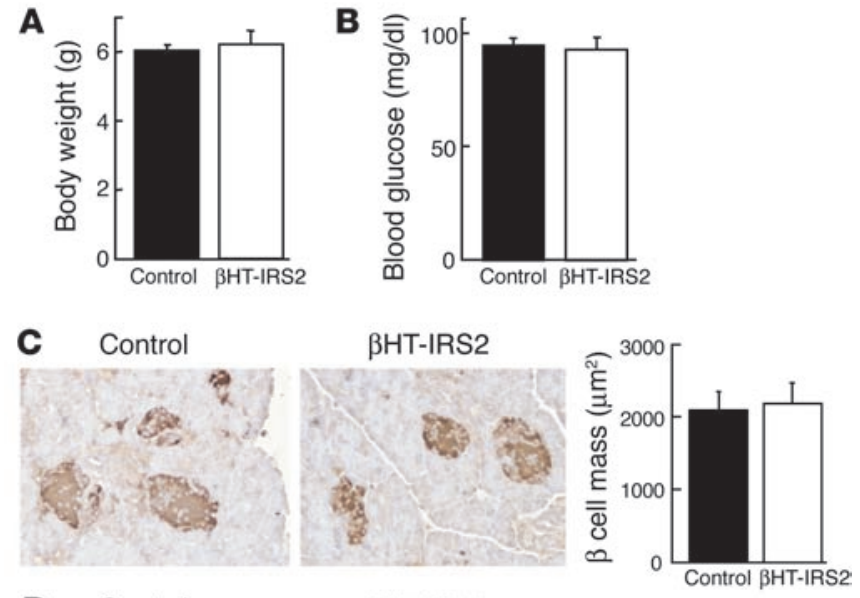

D Control
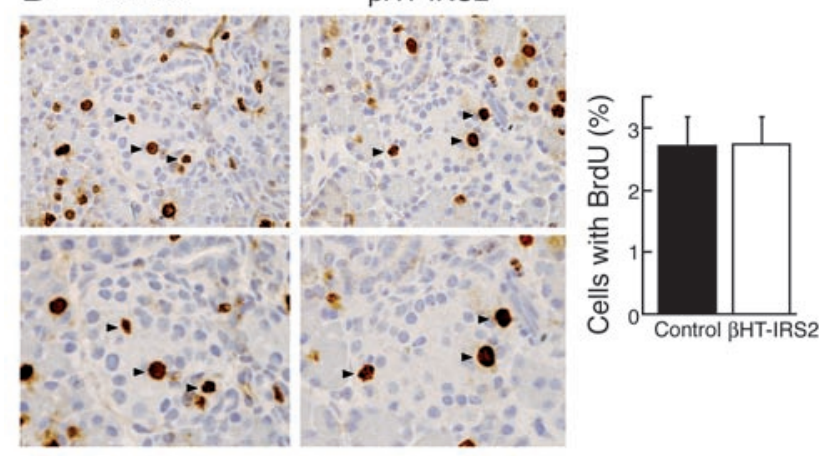
A
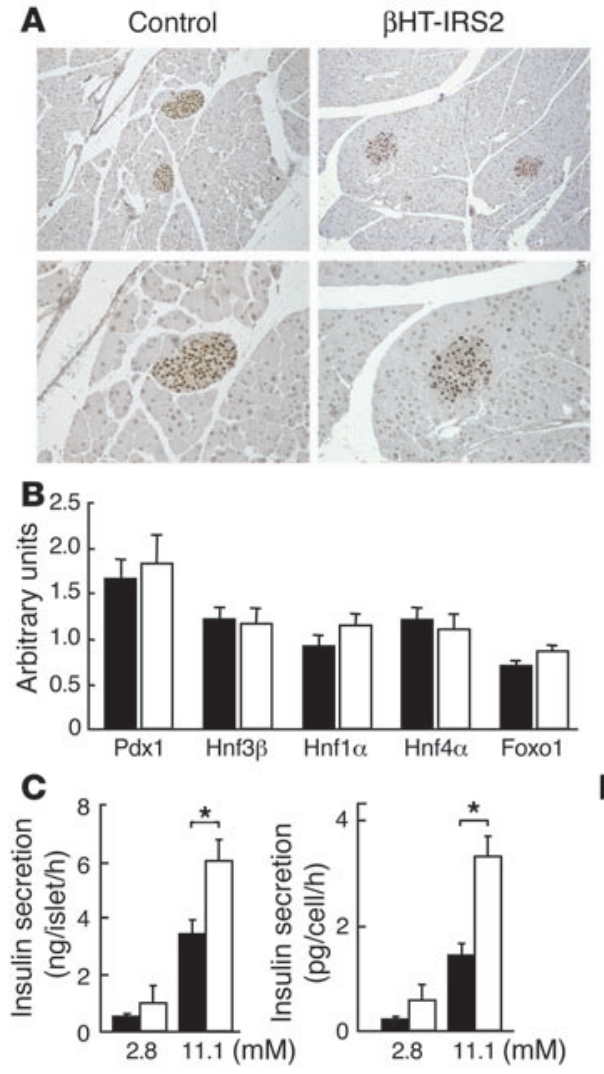

E

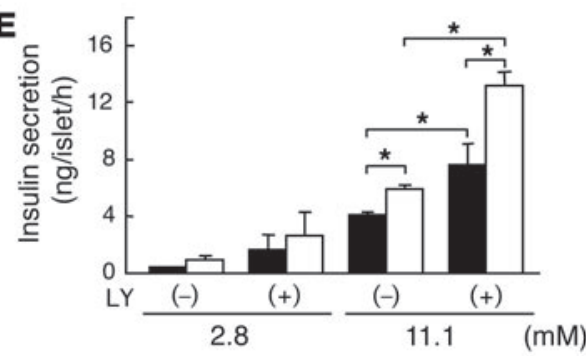

Control
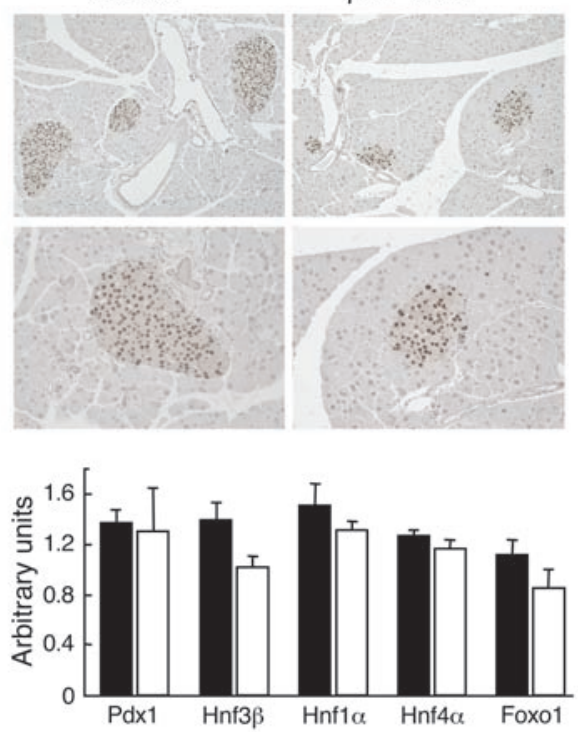

D

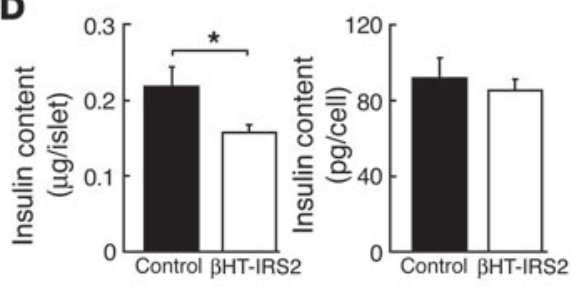

$(\mathrm{mM})$

$\beta \mathrm{HT}$-IRS2

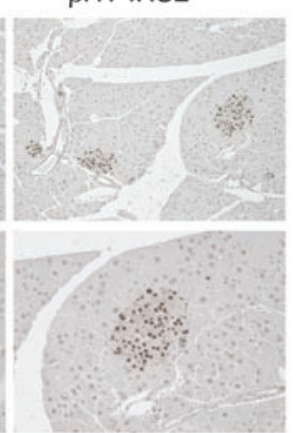

mice (white bars) at 8 weeks (left) and at 12 weeks (right). (C) Insulin secretion per islet (left) and insulin secretion normalized by cell number per islet (right) during static incubation of islets from control and $\beta$ HT-IRS2 mice for 1 hour at the glucose levels indicated. Values are expressed as means \pm SE $(n=5)$. Data were obtained in 3 independent experiments. (D) Insulin content per islet (left) and insulin content normalized by cell number per islet (right) in control and $\beta \mathrm{HT}$-IRS2 mice. Values are expressed as means \pm SE $(n=5)$. Data were obtained in 3 independent experiments. (E) Insulin secretion per islet during static incubation of islets from control and $\beta \mathrm{HT}$-IRS2 mice for 1 hour at the glucose levels indicated with and without LY294002 (LY). Data were obtained in 3 independent experiments. ${ }^{*} P<0.05$.
4 weeks of age, and then they were fed a high-fat diet for 4 weeks. The body weight and WAT mass of the epididymal fat pads of $\beta$ HTIRS2 mice were significantly higher than those of the control mice (Figure 8A). $\beta$ HT-IRS2 mice developed type 2 diabetes, as fasting glucose levels were slightly but significantly higher than those of control mice (Figure 8B). In insulin tolerance tests, the glucose lowering effect of insulin was significantly lower in $\beta$ HT-IRS2 mice than in control mice (Figure 8C). We performed histological and immunohistological analyses of pancreatic islets. The $\beta$ cell mass of $\beta$ HT-IRS2 mice was significantly reduced as compared with that of control mice (Figure 8D). We next investigated Pdx1 expression levels. Immunohistochemical studies revealed $\mathrm{Pdx} 1$ protein to be equally expressed in the nuclei of $\beta$ HT-IRS 2 mice and control mice (Figure 8E), despite the development of type 2 diabetes in the mutant mice. Taqman PCR revealed that the expression levels of Pdx1 mRNA in the $\beta$ HT-IRS2 mice were slightly, but not significantly, lower than those in control mice (Figure 8F).

\section{Discussion}

We and others have demonstrated that Irs $2^{-/-}$mice develop type 2 diabetes as a result of an insulin signaling defect in the liver and inadequate $\beta$ cell hyperplasia $(11,13)$, and $\operatorname{Irs} 2^{-/-}$mice exhibit obesity, probably due to a leptin signaling defect in the hypothalamus $(12,14)$. To dissect the complex and interacting pathways leading to the development of diabetes, we attempted to disrupt the Irs 2 gene in a tissue-specific fashion by using Cre-lox technology. To elucidate the role of Irs 2 in $\beta$ cells and the hypothalamus, we herein crossed Irs $2^{\text {lox } / l o x}$ mice with RIP-Cre mice $(16,17)$. Expression of Irs 2 mRNA was markedly reduced in both islets and the arcuate nucleus of the hypothalamus, but expressions were comparable in hepatic, muscle, and adipose tissues of $\beta$ HTIRS 2 and control mice. Conventional Irs $2^{-/-}$mice exhibited obesity associated with leptin resistance $(12,14)$, resulting from the attenuation of leptin signaling, which occurs with the absence of Irs2 in the hypothalamic area (18).

The striking feature of the $\beta$ HT-IRS2 mice is that they exhibited a metabolic syndrome consisting of obesity, leptin resistance, insulin resistance, glucose intolerance, and dyslipidemia. Irs2 expression in $\beta$ HT-IRS 2 mice was markedly reduced in the arcuate nucleus area, where in situ hybridization showed leptin receptors to be densely expressed (Figure 2E), suggesting that lack of Irs2 in leptin-responsive neurons in the arcuate nucleus is the primary 
cause of leptin resistance and obesity in $\beta$ HT-IRS2 mice. Based on these findings, together with a recent report that Stat 3 floxed mice exhibit obesity and leptin resistance (19), it seems that Stat3 and the Irs2/PI3K pathway in leptin-sensitive neurons in the arcuate nucleus are both necessary for the maintenance of normal body weight. However, the insulin receptor is known to be expressed in the arcuate nucleus area. Furthermore, insulin signaling and leptin signaling both regulate food intake and energy homeostasis (20). Since not only leptin signaling but also insulin signaling was attenuated in hypothalami from $\beta$ HT-IRS2 mice (Figure 2F), we cannot rule out the possibility that a lack of Irs2 in the arcuate nucleus could lead to obesity via insulin signaling rather than leptin signaling.

$\beta$ HT-IRS2 mice have a decreased $\beta$ cell mass due to blunted cell growth, as manifested by decreased BrdU incorporation into DNA in $\beta$ cells (Figure 4). However, at 10 days of age, both $\beta$ cell mass and BrdU incorporation into DNA in the $\beta$ HT-IRS2 mice and control mice were comparable (Figure 6). Irs2 may be required for some growth stimulatory signal after weaning, when the primary source of energy changes from lipids to glucose.

It has previously been demonstrated that the 129/Sv background affects diabetic phenotype, $\beta$ cell morphology, and Pdx1 expression in Irs $2^{-/-}$mice $(15,21,22)$. Why did type 2 diabetes not develop in $\beta$ HT-IRS2 mice despite their 129/Sv background? One possible explanation is that, unlike Irs $2^{-/-}$mice, $\beta$ HT-IRS2 mice maintained Irs2 expression in tissues other than $\beta$ cells and the hypothalamus. Why were Pdx1 expression levels unaltered in $\beta$ HT-IRS2 mice despite their $129 /$ Sv background? Since Irs $2^{-/-}$mice with the 129/Sv background showed reduced Pdx1 expression in the context of marked hyperglycemia (22), we hypothesized that reduced $\mathrm{Pdx} 1$ expression can be caused by a combination of 129/Sv background and hyperglycemia. Thus, we conducted a high-fat diet experiment. Although $\beta$ HT-IRS2 mice developed type 2 diabetes after 4 weeks on a high-fat diet, diabetic severity was much less than that of Irs2 $2^{-/}$mice with the $129 /$ Sv background (22). However, the expression levels of $\mathrm{Pdx} 1 \mathrm{mRNA}$ in the $\beta$ HT-IRS2 were not significantly lower than those of control mice. Whether or not $\beta$ HT-IRS2 mice show significantly decreased Pdx1 expres-

\section{Figure 8}

sion levels when they develop a more severe degree of hyperglycemia requires further investigation.

It is noteworthy that glucose-stimulated insulin secretion by islets was greater in $\beta$ HT-IRS2 mice than it was in control mice. We initially hypothesized that the increased glucose-stimulated insulin secretion in conventional Irs $2^{-/-}$mice was caused by insulin resistance, but the results of this study indicate that signals other than insulin resistance may be responsible for this increase. In contrast to conventional Irs $2^{-/-}$and $\beta$ HT-IRS 2 mice, Irs $1^{-/-}$mice

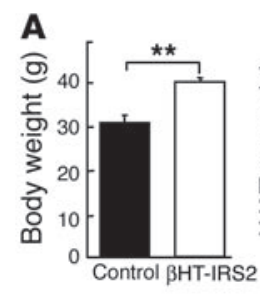

D Control

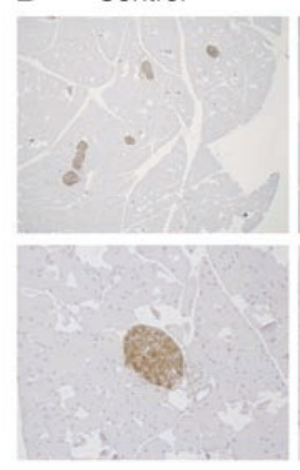

E Control
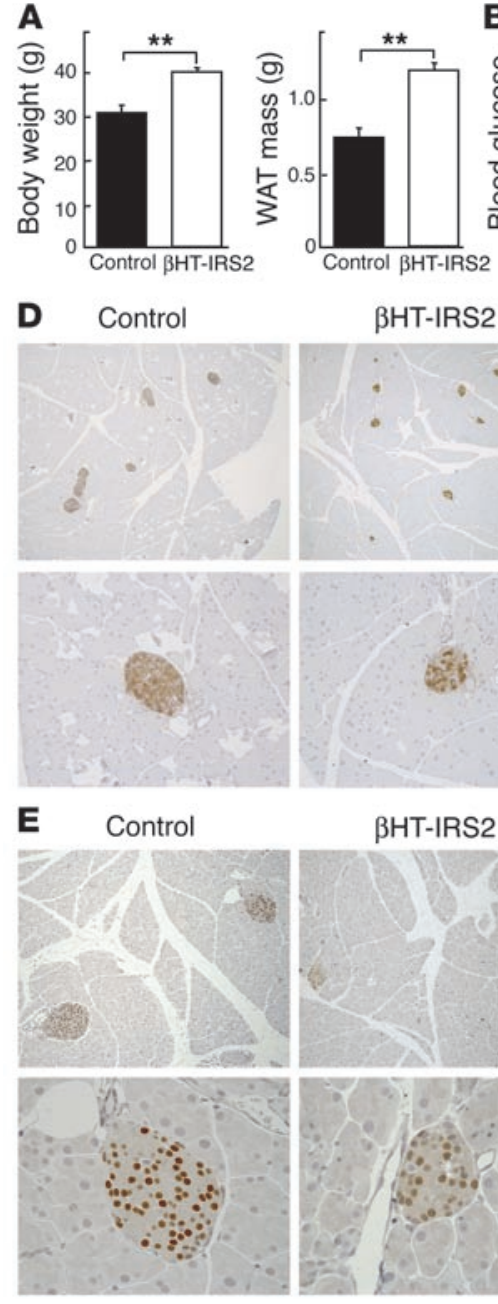

BHT-IRS2

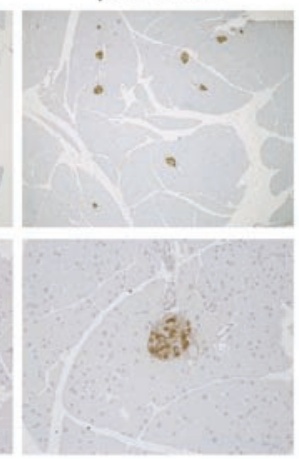

$\beta H T-I R S 2$

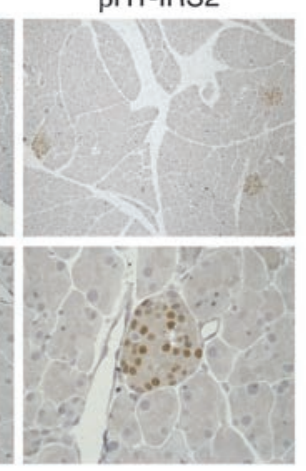

B $\quad$ C

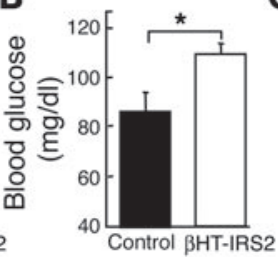

2 득

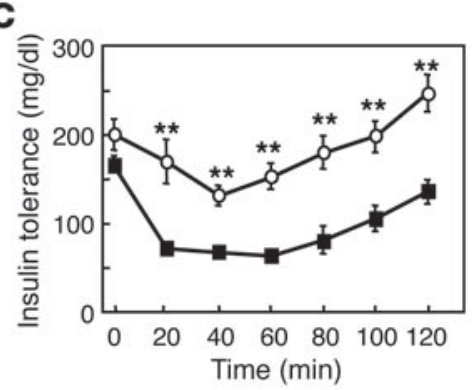

$\beta \mathrm{HT}$-IRS2 mice on a high-fat diet for 4 weeks, starting from 4 weeks of age. (A) Body weights (left) and WAT mass of epididymal fat pads (right) of control and $\beta \mathrm{HT}$-IRS2 mice. Values are means $\pm \mathrm{SE}$ of data obtained from the analysis of control (black bars, $n=7$ ) and $\beta$ HT-IRS2 mice (white bars, $n=7)$. (B) Fasting blood glucose levels of control and $\beta \mathrm{HT}$-IRS2 mice. Values are means $\pm \mathrm{SE}$ of data obtained from the analysis of control (black bars, $n=7$ ) and $\beta$ HT-IRS2 mice (white bars, $n=7$ ). (C) Insulin tolerance tests of control and $\beta$ HT-IRS2 mice. Values are means \pm SE of data obtained from the analysis of control (filled squares, $n=7$ ) and $\beta$ HT-IRS2 mice (open circles, $n=7$ ). (D) Histological analysis of pancreatic islets (left) and quantitation of $\beta$ cell mass (right) in control and $\beta$ HT-IRS2 mice. Representative islets viewed on a computer monitor are shown. Results are shown as area of $\beta$ cell mass. Values are means \pm SE of data obtained from the analysis of control (black bar, $n=5$ ) and $\beta$ HT-IRS2 mice (white bar, $n=5$ ). Original magnification, $\times 40$ (upper panels); $\times 100$ (lower panels). (E) Immunohistochemical study of Pdx1 in control and $\beta \mathrm{HT}$-IRS2 mice. Representative islets viewed on a computer monitor are shown. Original magnification, $\times 100$ (upper panels); $\times 200$ (lower panels). (F) Taqman PCR analysis of $\mathrm{Pdx} 1, \mathrm{Hnf} 1 \alpha, \mathrm{Hnf} 4 \alpha$, and Foxo1 mRNA levels, normalized to $\beta$-actin mRNA levels in control (black bars) and $\beta \mathrm{HT}$-IRS2 mice (white bars). ${ }^{*} P<0.05 ;{ }^{* *} P<0.01$. 
develop $\beta$ cell hyperplasia but exhibit impaired glucose-stimulated insulin secretion by individual islets and $\beta$ cells $(7,13,23-25)$. Mutations in Irs 1 in humans also lead to impaired insulin secretion (26). Moreover, $\beta$ cell-specific insulin receptor $\mathrm{KO}$ mice show a defect in glucose-induced insulin secretion (16). $\beta$ Cells from mice deficient in the PI3K p85 regulatory subunit and $\beta$ cells treated with PI3K inhibitor exhibit a marked increase in the insulin secretory response to glucose (27). These findings suggest that insulin receptors acting through Irs1 stimulate insulin secretion, whereas the Irs2/PI3K pathway suppresses it. However, since insulin secretion was increased by LY294002, an inhibitor of PI3K, in $\beta$ HT-IRS2 mice as well as in control mice, as we previously reported (27), the suppressive effect of Irs 2 on insulin secretion is apparently not exerted through PI3K. Conventional Irs $2^{-/-}$and $\beta$ HT-IRS2 mice exhibited leptin resistance. Leptin has been reported to decrease insulin secretion (28). Thus, we cannot rule out the possibility that decreased leptin activity led to the increased insulin secretion in conventional Irs $2^{-/-}$and $\beta$ HT-IRS 2 mice. In a future investigation, we plan to generate and analyze mice that are specifically deficient in Irs 2 in $\beta$ cells but not in the hypothalamus.

Unlike Irs $2^{-/-}$mice, which develop diabetes at 10 weeks of age, $\beta$ HT-IRS2 mice do not become diabetic. This indicates that $\beta$ cell dysfunction and obesity due to hypothalamic dysfunction are insufficient for the development of diabetes. In fact, it was previously demonstrated that hepatic Irs 2 restoration in Irs $2^{-/-}$mice, using an adenoviral vector, prevented the development of diabetes (18). This observation indicates that absence of Irs 2 in the hypothalamus and $\beta$ cells is insufficient for the development of diabetes.

\section{Methods}

Construction of targeting vector, ES cell culture, and generation of mutant mice. To construct the targeting vectors for the Irs2 gene, a 129/Sv mouse genomic DNA library packaged in Lambda DASH II (BD Biosciences - Clontech) was screened with 5 '-side and 3 '-side mouse genomic DNA as probes (probes $\mathrm{C}$ and $\mathrm{B}$, respectively, in Figure 1A). Probe $\mathrm{C}$ isolated 3 clones containing Irs2, and probe B was used to isolate 4 clones containing this gene. We constructed 2 targeting vectors (tv's): tv- 1 was the floxed neomycin-resistance gene introduced into the $3^{\prime}$ side of the Irs 2 gene, and tv-2 was introduced into the $5^{\prime}$ side (Figure 1A). First, we transfected tv-1 into J1 embryonic stem cells $(129 / \mathrm{Sv})$ by electroporation and screened them for homologous recombinant clones by Southern blot analysis, as described previously (29) (Figure 1B, left panel). Next, the closed circular pCre-Pac DNA was transfected by electroporation into the homologous recombinant clone to delete the floxed neoR of $\mathrm{tv}-1$ by a method described elsewhere with minor modifications (30), and the deletion of neoR was confirmed by Southern blot analysis (Figure 1B, middle panel). Finally, tv-2 was electroporated into the recombinant clone lacking neoR, and we screened again for homologous recombinant clones by Southern blot analysis (Figure 1B, right panel).

The cells were injected into blastocysts from $\mathrm{C} 57 \mathrm{Bl} / 6$ mice and transferred into pseudopregnant ICR females to generate chimeric mice (29). Male chimeric mice with agouti coat color were mated with $\mathrm{C} 57 \mathrm{Bl} / 6$ female mice to generate heterozygous $\left(\operatorname{Irs} 2^{l o x /+}\right)$ mice (estimated contribution of each genetic background: 50\% 129/Sv and 50\% C57Bl/6) (29).

Animals and genotyping. Mice were housed on a 12-hour light-dark cycle and were given either Regular Chow CE-2 (CLEA Japan Inc.) consisting of $25.6 \%$ (wt/wt) protein, $3.8 \%$ fiber, $6.9 \%$ ash, $50.5 \%$ carbohydrates, $4 \%$ fat, and 9.2\% water, or High-Fat Diet 32 (CLEA Japan Inc.), consisting of $25.5 \%$ (wt/wt) protein, $2.9 \%$ fiber, $4.0 \%$ ash, $29.4 \%$ carbohydrates, $32 \%$ fat, and $6.2 \%$ water. RIP-Cre mice $(\mathrm{C} 57 \mathrm{Bl} / 6)$ were purchased from the Jack- son Laboratory. We bred Irs $2^{\text {lox/+ }}$ mice (50\% 129/Sv, 50\% C57Bl/6) with RIP-Cre mice (C57Bl/6), and then bred the Irs $2^{\text {lox/+ }} /$ RIP-Cre offspring $(25 \%$ $129 / \mathrm{Sv}, 75 \% \mathrm{C} 57 \mathrm{Bl} / 6)$ with Irs $2^{\text {lox/+ }}$ mice $(25 \% 129 / \mathrm{Sv}, 75 \% \mathrm{C} 57 \mathrm{Bl} / 6)$ to generate Irs2 $2^{\text {lox/lox}} / \mathrm{RIP}-\mathrm{Cre}$ mice (25\% 129/Sv, 75\% C57Bl/6), which have the same genetic background as those we used in a previous study (22). All experiments in this study were performed using littermate male mice. Genotyping was performed by PCR amplification of tail DNA from each mouse at 3 weeks of age. The primers for Cre recombinase were 5 -ACATGTTCAGGGATCGCCAGG-3' and 5'-TAACCAGTGAAACAGCATTGC-3', and the primers for the Irs2 and floxed Irs 2 alleles were $5^{\prime}$-CCAGTGGGTGGCAGTGTGGGTAGG-3', 5'-CAGCGCATCGCCTTCTATCGCCTTC-3', and 5'-GCCATGTCCTTACAACCATTAGCGG -3'. To detect Cre-mediated recombination at the genomic DNA levels of various tissues by PCR, we designed primers for the upstream portion of Irs 2 genomic DNA (primer a), Neo DNA (primer b), and the downstream portion of Irs2 genomic DNA (primer c) (see Figure 1A). Primer a was 5'-CCAGTGGGTGGCAGTGTGGGTAAGA-3', primer b was 5'-CAGCGCATCGCCTTCTATCGCCTT-3', and primer c was 5'-CCCATGTCTGCTTGTATGGAGAGCC$3^{\prime}$. These primer pairs give rise to PCR products of $0.2 \mathrm{~kb}$ and $0.4 \mathrm{~kb}$ before and after Cre-mediated Irs 2 deletion, respectively. The animal care and procedures of the experiments were approved by the Animal Care Committee of the University of Tokyo.

$R N A$ preparation and RT-PCR. Total RNA was prepared from various tissues with ISOGEN Reagent Total RNA isolation reagent (Nippon Gene Co.) according to the manufacturer's instructions. Comparative analysis of mRNA levels in different tissues was performed by RT-PCR. Total RNA was treated with RNase-free DNase (Nippon Gene Co.), and first-strand cDNA was generated with random 9-mer primers and reverse transcriptase (Takara Shuzo Co.). The reverse-transcription mixture was amplified with specific primers. The primers for Cre recombinase were as described above. The primers for Irs2 were 5'-GGTGCTAAGGTCATCCGTGCA-3' and 5'-TTTCACGACTGTGGCTTCCTTC-3', and the primers for 36B4 (control) were 5'-ATGCCCAGGGAAGACAGGGCGACC-3' and 5'-TTAGTCGAAGAGACCGAATCCCATA-3'.

Isolation of the hypothalamus. Dissections were performed on an ice-cooled glass plate. First, the rhombencephalon was separated by transverse section from the rest of the brain. A transverse section was made at the level of the optic chiasm, which delimits the anterior part of the hypothalamus and passes through the anterior commissure. The hypothalamus was dissected by using the anterior commissure as a horizontal reference, and the line between the posterior hypothalamus and the mammillary bodies was used as the caudal limit (31).

Immunoprecipitation and Western blot analysis. Immunoprecipitation and Western blot analysis were performed as described previously with some modifications (13). To assess the expression levels of Irs2, islets and hypothalami from $\beta$ HT-IRS2 and control mice were homogenized, and lysates were immunoprecipitated with anti-Irs2 antibody. Samples were then separated on polyacrylamide gels and transferred to a Hybond-P PVDF transfer membrane (Amersham Biosciences).

For detection of Akt and Stat3 phosphorylation, human regular insulin (5 units/mouse) and leptin (10 mg/kg/injection) (PeproTech EC Ltd.) were injected into the tail vein after mice were fasted for more than 16 hours. Fifteen minutes after insulin and 60 minutes after leptin injection, hypothalami were homogenized, and lysates were separated on polyacrylamide gels and transferred to a Hybond-P PVDF transfer membrane (Amersham Biosciences). The membranes were incubated with the indicated antisera and HRP-conjugated anti-IgG antibodies. Bands were detected with ECL detection reagents (Amersham Biosciences).

Leptin and lipid measurements. Mice were fasted for more than 16 hours before the measurements. Serum leptin levels were determined with a 
Quantikine M kit (R \& D Systems Inc.). Serum total cholesterol triglyceride and free fatty acids (Wako Pure Chemical Industries Ltd.) were assayed by enzymatic methods.

Leptin sensitivity. $\beta$ HT-IRS2 and control mice were injected intraperitoneally once a day at 21:00 with control saline or leptin $(10 \mathrm{mg} / \mathrm{kg} /$ injection; PeproTech EC Ltd.), and their body weights and food intakes were then monitored (32). The statistical significance of differences in body weight and food intake between groups was determined by Student's $t$ test (2-tailed).

Caloric restriction experiment. Four-week-old $\beta$ HT-IRS2 and control mice were kept in individual cages and 3.5 grams of regular chow were provided at the end of the light cycle (21:00) every day for the first week and then 4.0 grams for the second through fourth weeks. The day before starting the experiments, the mice were given ad libitum access to chow for 12 hours of the dark cycle to avoid prolonged fasting conditions.

Generation of cRNA probes for Irs 2 and leptin receptor. The PCR products were ligated to the vector with a TA cloning kit (Invitrogen Corp.). ${ }^{35} \mathrm{~S}$-labeled riboprobes were generated from the fragments of PCR products for Irs2 and the leptin receptor using a Sp6/T7 transcription kit according to the manufacturer's instructions (Boehringer Mannheim $\mathrm{GmbH}$ ). Antisense probes for Irs2 and the leptin receptor were generated by using T7 and Sp6 polymerases, respectively, and sense probes for Irs2 and the leptin receptor were generated by using Sp6/T7 polymerase (33).

In situ bybridization and histochemistry. Frozen $12-\mu \mathrm{m}$-thick sections from mouse brain that included the hypothalamus were cut in a cryostat at $-20^{\circ} \mathrm{C}$, and after thaw mounting onto gelatin-chrome alum-coated slides, these sections were stored at $-80^{\circ} \mathrm{C}$. Frozen tissue sections were allowed to dry in air for 10 minutes and were then fixed in $4 \%$ formaldehyde in PBS ( $\mathrm{pH} 7.5$ ) for 5 minutes and washed twice in PBS. Fixed tissue sections were incubated for 10 minutes in $0.9 \%$ saline containing $0.1 \mathrm{M}$ triethanolamine and $0.25 \%$ acetic anhydride, then dehydrated by transferring them sequentially through $70 \%$ (1 minute), $80 \%$ (1 minute), $95 \%$ ( 2 minutes), and 100\% ethanol ( 1 minute); and delipidated in $100 \%$ chloroform for 5 minutes. The slides were partially dehydrated in $100 \%$ ethanol ( 1 minute) followed by 95\% (1 minute) ethanol, and allowed to dry briefly in air. Hybridization was carried out at $50^{\circ} \mathrm{C}$ overnight in $46 \mu \mathrm{l}$ buffer consisting of the following: 42 $\mu \mathrm{l}$ of $23.9 \mathrm{mM}$ TrisCl, $0.63 \mathrm{mM}$ EDTA, $359.7 \mathrm{mM} \mathrm{NaCl}, 59.4 \%$ formamide, $12 \%$ dextran sulphate $(500,000 \mathrm{~mol} w \mathrm{t})$, and $2.4 \%$ Denhardt's solution; $2 \mu \mathrm{l}$ of a solution of $2.5 \mathrm{mg} / \mathrm{ml}$ sheared salmon sperm DNA (SigmaAldrich) and $5 \mathrm{mg} / \mathrm{ml}$ yeast total RNA (Sigma-Aldrich); and about $2 \mu \mathrm{l}$ of ${ }^{35} \mathrm{~S}$-labeled antisense and sense probes $\left(1 \times 10^{6} \mathrm{cpm}\right.$ per slide) under Nescofilm (Bando Chemical IMD) coverslips $(33,34)$. The slides were rinsed in $2 \times$ SSC ( $1 \times$ SSC: $150 \mathrm{mM} \mathrm{NaCl}, 15 \mathrm{mM}$ sodium citrate) and washed for 30 minutes in 2 changes of $2 \times \mathrm{SSC}$ containing $50 \%$ formamide at $50^{\circ} \mathrm{C}$ before being incubated at $37^{\circ} \mathrm{C}$ in $2 \times \mathrm{SSC}$ containing $20 \mu \mathrm{l} / \mathrm{ml}$ RNase A (SigmaAldrich). After a further 45 minutes wash in 3 changes of $2 \times \mathrm{SSC}$ containing $50 \%$ formamide at $50^{\circ} \mathrm{C}$, the slides were washed for 10 minutes in 2 changes of $2 \times \mathrm{SSC}$ at room temperature, and after being briefly dipped in water and $70 \%$ ethanol, they were air dried. Slides hybridized to the riboprobes were exposed to films for 3 days. Irs 2 transcript hybridized sections were exposed to autoradiography film (Hyperfilm, Amersham Biosciences). The resulting images were analyzed by computerized densitometry using a MCID imaging analyzer (Imaging Research Inc.). The mean optical density of autoradiographs was measured by comparing it with simultaneously exposed $\left[{ }^{14} \mathrm{C}\right]$ micro-scale samples (Amersham Biosciences).

In vivo glucose homeostasis. Glucose and insulin tolerance tests were performed according to methods described previously (32).

Histological and immunohistochemical analysis of islets. Four male mice at 10 days and five male mice at 12 weeks were used for each genotype, and sections of the pancreas were evaluated morphometrically. For the immunohistochemical analysis, pancreatic sections were stained with anti- insulin (DakoCytomation Co.) or anti-Pdx1 antibodies (35), and the areas of the islets were traced manually and analyzed with Win ROOF software (Mitani Co.) as previously described (10). More than 50 islets were analyzed per mouse in each group.

Cell proliferation. BrdU (100 mg/ $\mathrm{kg}$ in saline) was injected intraperitoneally, and 6 hours later, the mice were perfused with $4 \%$ paraformaldehyde and their pancreata were fixed in $4 \%$ paraformaldehyde in PBS. Immunohistochemical staining techniques were performed with a Cell Proliferation Kit (Amersham Biosciences) according to a previously described method (36). For immunohistochemistry, sections were fixed in $4 \%$ paraformaldehyde for 10 minutes at room temperature, embedded in paraffin, sectioned at $2 \mu \mathrm{m}$, and counterstained with hematoxylin. Labeled cells and total cells in the islets were counted in 3 sections per specimen, and labeling indices were calculated as the labeled cell to total cell ratio of islets from more than 4 specimens per group.

Single-strand DNA analysis in islets. Mice were perfused with $4 \%$ paraformaldehyde and their pancreata were fixed in $4 \%$ paraformaldehyde at $4{ }^{\circ} \mathrm{C}$ overnight, embedded in paraffin, and cut into $2-\mu \mathrm{m}$-thick sections. The sections were blocked with $10 \%$ calf serum in PBS for 20 minutes and then incubated with polyclonal antibody against single-strand DNA for 30 minutes at room temperature. Goat serum instead of single-strand DNA antibody was used for negative controls. The streptavidin-biotin complex method with an LSAB kit (DakoCytomation Co.) was used for immunohistochemistry according to the manufacturer's instructions.

Taqman PCR. Quantitative analysis of mRNA levels in islets and the hypothalamus was performed by fluorescence-based RT-PCR. The reversetranscription mixture was amplified with specific primers using an ABI Prism 7000 sequence detector equipped with a thermocycler. The primers used for Pdx1, Hnf $3 \beta, \operatorname{Hnf} 1 \alpha, \operatorname{Hnf} 4 \alpha$, Foxo1, and $\beta$-actin were as described previously (22). Relative expression levels were compared between $\beta$ HT-IRS2 and control mice after normalization to $\beta$-actin.

Islet isolation and $\beta$ cell preparation. Isolation of islets from mice of each genotype was carried out as described previously with some modifications (13). After clamping the common bile duct at a point close to its opening into the duodenum, we injected collagenase (Sigma-Aldrich) into the pancreatic duct. The swollen pancreas was removed and incubated at $37^{\circ} \mathrm{C}$ for 3 minutes. The pancreas was dispersed by pipetting, and dispersed cells were washed twice with Krebs-Ringer bicarbonate buffer. Single cells were isolated with Trypsin-EDTA (Invitrogen Corp.), as previously described (13).

Analysis of insulin content and secretion. Insulin content and secretion were measured as described previously with slight modifications (13). Isolated islets were extracted in acid ethanol at $-20^{\circ} \mathrm{C}$, and after preincubation with the basal glucose concentration for 20 minutes, static incubation of 10 islets/tube was performed at $37^{\circ} \mathrm{C}$ for 1 hour (13). Insulin levels were determined with an insulin RIA kit (Amersham Biosciences) (32). The islet cells were counted with a hemacytometer. When LY294002 was added to incubation media, it was also included in preincubation media.

Antibodies and chemicals. Rabbit polyclonal antibodies to Irs2 were purchased from Upstate Biotechnology. Rabbit polyclonal antibodies to Akt, phospho-Akt, Stat3, and phospho-Stat 3 were purchased from Cell Signaling Technology. Rabbit polyclonal antibodies against single-strand DNA was purchased from DakoCytomation. LY294002 was purchased from Sigma-Aldrich.

Statistical analysis. Values are expressed as means \pm SE. The statistical significance of differences between groups was determined by Student's $t$ test (2-tailed).

\section{Acknowledgments}

We thank Yoshinobu Sugitani, Shioko Itoh, Hitomi Yamanaka, Katsuko Takasawa, Eri Yoshida-Nagata, Norie Ohtsuka-Kowa- 
tari, Ayumi Nagano, Miharu Nakashima, and Hiroshi Chiyonobu for their excellent technical assistance and animal care. This work was supported by a grant for Life \& Socio-Medical Sciences from the Kanae Foundation (to N. Kubota), a grant from the Tanabe Medical Frontier Conference, a grant-in-aid for Scientific Research on Priority Areas (B) from the Ministry of Education, Culture, Sports, Science and Technology of Japan (to Y. Terauchi), a grant-in-aid for Creative Scientific Research (10NP0201) from the Japan Society for the Promotion of Science, a grant from the Juvenile Diabetes Foundation International (1-2003-746), a grant-in-aid for the Development of Innovative Technology from the Ministry of Education, Culture, Sports, Science and Technology of Japan, and health science research grants (Research on
Human Genome and Gene Therapy) from the Ministry of Health and Welfare of Japan (to T. Kadowaki).

Received for publication March 3, 2004, and accepted in revised form July 20, 2004.

Address correspondence to: Takashi Kadowaki, Department of Metabolic Diseases, Graduate School of Medicine, University of Tokyo, 7-3-1 Hongo, Bunkyo-ku, Tokyo 113-8655, Japan. Phone: 81-3-3815-5411 ext. 33111; Fax: 81-3-5689-7209; E-mail: kadowaki-3im@h.u-tokyo.ac.jp.

Yasuo Terauchi and Kazuyuki Tobe contributed equally to this work.
1. Kadowaki, T. 2000. Insights into insulin resistance and type 2 diabetes from knockout mouse models. J. Clin. Invest. 106:459-465.

2. White, M.F. 1998. The IRS-signalling system: a network of docking proteins that mediate insulin action. Mol. Cell. Biochem. 182:3-11.

3. Virkamaki, A., Ueki, K., and Kahn, C.R. 1999. Protein-protein interaction in insulin signaling and the molecular mechanisms of insulin resistance. J. Clin. Invest. 103:931-943.

4. Saltiel, A.R., and Kahn, C.R. 2001. Insulin signalling and the regulation of glucose and lipid metabolism. Nature. 414:799-806.

5. Nakae, J., Kido, Y., and Accili, D. 2001. Distinct and overlapping functions of insulin and IGF-I receptors. Endocr. Rev. 22:813-835.

6. Shulman, G.I. 2000. Cellular mechanisms of insulin resistance. J. Clin. Invest. 106:171-176.

7. Mauvais-Jarvis, F., Kulkarni, R.N., and Kahn, C.R. 2002. Knockout models are useful tools to dissect the pathophysiology and genetics of insulin resistance. Clin. Endocrinol. (Oxf). 57:1-9.

8. Tamemoto, H., et al. 1994. Insulin and growth retardation in mice lacking insulin receptor substrate-1. Nature. 372:182-186

9. Araki, E., et al. 1994. Alternative pathway of insulin signalling in mice with targeted disruption of the IRS-1 gene. Nature. 372:186-190.

10. Terauchi, Y., et al. 1997. Development of noninsulin-dependent diabetes mellitus in the double knockout mice with disruption of insulin receptor substrate- 1 and beta cell glucokinase genes. Genetic reconstitution of diabetes as a polygenic disease. J. Clin. Invest. 99:861-866.

11. Withers, D.J., et al. 1998. Disruption of IRS2 causes type 2 diabetes in mice. Nature. 391:900-904.

12. Withers, D.J., et al. 1999. Irs 2 coordinates Igf-1 receptor-mediated beta-cell development and peripheral insulin signalling. Nat. Genet. 23:32-40.

13. Kubota, N., et al. 2000. Disruption of insulin receptor substrate 2 causes type 2 diabetes because of liver insulin resistance and lack of compensatory beta-cell hyperplasia. Diabetes. 49:1880-1889.

14. Tobe, K., et al. 2001. Increased expression of the sterol regulatory element-binding protein-1 gene in insulin receptor substrate-2-/- mouse liver. J. Biol. Chem. 276:38337-38340.

15. Terauchi, Y., et al. 2003. Impact of genetic background and ablation of insulin receptor substrate (IRS)-3 on IRS-2 knock-out mice. J. Biol. Chem. 278:14284-14290.

16. Kulkarni, R.N., et al. 1999. Tissue-specific knockout of the insulin receptor in pancreatic beta cells creates an insulin secretory defect similar to that in type 2 diabetes. Cell. 96:329-339.

17. Kulkarni, R.N., et al. 2002. Beta-cell-specific deletion of the Igf1 receptor leads to hyperinsulinemia and glucose intolerance but does not alter beta-cell mass. Nat. Genet. 31:111-115.

18. Suzuki, R., et al. 2004. Both insulin signaling defects in the liver and obesity contribute to insulin resistance and cause diabetes in irs $2^{-/-}$mice. J. Biol. Chem. 279:25039-25049.

19. Cui, Y., et al. 2004. Essential role of STAT3 in body weight and glucose homeostasis. Mol. Cell. Biol. 24:258-269.

20. Bruning, J.C., et al. 2000. Role of brain insulin receptor in control of body weight and reproduction. Science. 289:2122-2125.

21. Kushner, J.A., et al. 2002. Pdx1 restores beta cell function in Irs2 knockout mice. J. Clin. Invest. 109:1193-1201. doi:10.1172/JCI200214439.

22. Suzuki, R., et al. 2003. Pdx1 expression in Irs2-deficient mouse beta-cells is regulated in a strain-dependent manner. J. Biol. Chem. 278:43691-43698.

23. Aspinwall, C.A., Lakey, J.R., and Kennedy, R.T. 1999. Insulin-stimulated insulin secretion in single pancreatic $\beta$ cells. J. Biol. Chem. 274:6360-6365.

24. Kulkarni, R.N., et al. 1999. Altered function of insulin receptor substrate-1-deficient mouse islets and cultured beta-cell lines. J. Clin. Invest. 104:R69-R75.

25. Accili, D. 2001. A kinase in the life of the $\beta$ cell. J. Clin. Invest. 108:1575-1576. doi:10.1172/JCI200114454.

26. Porzio, O., et al. 1999 . The Gly972 $\rightarrow$ Arg amino acid polymorphism in IRS-1 impairs insulin secretion in pancreatic $\beta$-cells. J. Clin. Invest. 104:357-364.

27. Eto, K., et al. 2002. Phosphatidylinositol 3-kinase suppresses glucose-stimulated insulin secretion by affecting post-cytosolic $[\mathrm{Ca}(2+)]$ elevation signals. Diabetes. 51:87-97.

28. Kulkarni, R.N., et al. 1997. Leptin rapidly suppresses insulin release from insulinoma cells, rat and human islets and, in vivo, in mice. J. Clin. Invest. 100:2729-2736.

29. Kubota, N., et al. 2002. Disruption of adiponectin causes insulin resistance and neointimal formation. J. Biol. Chem. 277:25863-25866.

30. Taniguchi, M., et al. 1998. Efficient production of Cre-mediated site-directed recombinants through the utilization of the puromycin resistance gene, pac: a transient gene-integration marker for ES cells. Nucleic Acids Res. 26:679-680.

31. Glowinski, J., and Iversen, L.L. 1966. Regional studies of catecholamines in the rat brain. I. The disposition of $[3 \mathrm{H}]$ norepinephrine, $[3 \mathrm{H}]$ dopamine and $[3 \mathrm{H}]$ dopa in various regions of the brain. J. Neurochem. 13:655-669.

32. Kubota, N., et al. 1999. PPAR gamma mediates high-fat diet-induced adipocyte hypertrophy and insulin resistance. Mol. Cell. 4:597-609.

33. Ueta, Y., Levy, A., Chowdrey, H.S., and Lightman, S.L. 1995. S-100 antigen-positive folliculostellate cells are not the source of IL- 6 gene expression in human pituitary adenomas. J. Neuroendocrinol. 7:467-474.

34. Ueta, Y., Levy, A., Chowdrey, H.S., and Lightman, S.L. 1995. Hypothalamic nitric oxide synthase gene expression is regulated by thyroid hormones. Endocrinology. 136:4182-4187.

35. Offield, M.F., et al. 1996. PDX-1 is required for pancreatic outgrowth and differentiation of the rostral duodenum. Development. 122:983-995.

36. Ohtsuka, N., Urase, K., Momoi, T., and Nogawa, H. 2001. Induction of bud formation of embryonic mouse tracheal epithelium by fibroblast growth factor plus transferrin in mesenchyme-free culture. Dev. Dyn. 222:263-272. 